\title{
HISTOCHEMICAL STUDIES ON THE DEVELOPMENT OF CARPOPHORE OF POLYPORELLUS BRUMALIS (PERS. EX FR.) KARST.
}

\author{
MASAHIKO OKUNISHI AND KAZUO KOMAGATA ${ }^{1}$ \\ Central Research Laboratories, Ajinomoto Co., Inc., Kawasaki 210, Japan
}

(Received February 19, 1975)

\begin{abstract}
Developmental process of the carpophore of Polyporellus brumalis (Pers. ex Fr.) Karst. was histochemically observed. Locality of RNA, succinic dehydrogenase, cytochrome oxidase, esterase, peroxidase, and phosphatases was investigated. Acid phosphatase was stained intensively throughout the development of the carpophore but alkaline phosphatase was not detected. Acid phosphatase, esterase, peroxidase, cytochrome oxidase, and succinic dehydrogenase were detected in growth zones of this fungal carpophore, such as the apex of stipe, margin of pileus, and hymenial layers.
\end{abstract}

In a previous paper (1), the present authors demonstrated histochemically the locality of ribonucleic acid (RNA), succinic dehydrogenase (SDH), cytochrome oxidase, and acid and alkaline phosphatases in tissues of the carpophore of Coprinus kimurae Hongo et Aoki. These enzymes were detected in active growth zones of the carpophore. C. kimurae belongs to Agaricales, while Polyporellus brumalis (Pers. ex Fr.) Karst. used in this study belongs to Aphyllophorales taxonomically. In $C$. kimurae, the primordium develops into a minute bud which possesses stipe and pileus at an early stage of development. P. brumalis forms primordia which develop into tubular stipes, and pileus develops out of the apex of stipe at a later stage of development. It is of interest to compare the mode of development of carpophore histochemically in these basidiomycetous fungi.

This paper deals with the distribution of RNA, SDH, esterase, peroxidase, cytochrome oxidase, and phosphatases in tissues of the carpophore of $P$. brumalis in comparison with that of $C$. kimurae.

1 Present Address: The Institute of Applied Microbiology, University of Tokyo, Bunkyo$\mathrm{ku}$, Tokyo 113. 


\section{MATERIALS AND METHODS}

Organism. Polyporellus brumalis (Pers. ex Fr.) Karst. AJ 8269 used in this investigation was isolated from the fresh tissues of the carpophore obtained in October, 1965, at Yamanashi, Japan. This fungus has been maintained on a malt extract $(1.25 \%)$ agar slant.

Cultural conditions. This fungus was grown first at $25^{\circ}$ on a malt extract-agar plate for 14 days under continuous illumination with white light from a fluorescent tube, and then the temperature was lowered to $10^{\circ}$. Primordia of the carpophore formed at $10^{\circ}$ after about 9 days' incubation. The carpophores were collected at various stages of development and subjected to the following histochemical experiments.

Sectioning. The procedures were the same as those described previously (1).

Staining. Non-specific esterase was stained by Burstone's Naphthol AS-D acetate method (2), and peroxidase was stained by Gomori's benzidine method (2). RNA, SDH, cytochrome oxidase, and acid and alkaline phosphatases were stained by the methods described in the previous paper (1).

\section{RESULTS AND OBSERVATIONS}

Morphological observation of the development

A developmental process of the carpophore of $P$. brumalis was distinguished into 4 stages as shown in Fig. 1.

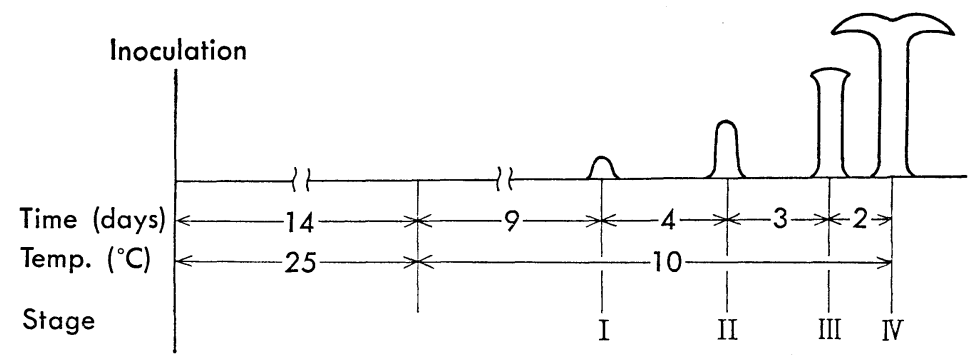

Fig. 1. Stages in carpophore development of Polyporellus brumalis.

Stage I: Budding stage. (Primordia of the carpophore form after temperature was lowered to $10^{\circ}$.)

Stage II: Elongation of stipe.

Stage III: When the stipe attains a considerable length, pileus-primordium differentiates at the stipe-apex.

Stage IV: The pileus develops centrifugally, and hymenial pores (hymenial layers) appear at the basal region of the pileus. The pore field expands over the undersurface of the pileus from the basal region to the outer margin. Basi- 
diospores are detected at the basal region before the pileus formation is completed.

At stage I, the cells constituting carpophore were in a tangle, but vertical orientation of the cells was observed at the apex of the primordium of the carpophore. At stages III and IV, a cortex (the outer layers of stipe) was clearly distinguished morphologically from the central trama. The cortex was compactly composed of cells which oriented vertically. On the other hand, the cells in the central trama were tangled and their density was sparse.

\section{Distribution of $R N A$}

During the development, RNA was intensively stained in the zones of an apex of stipe, outer margin of pileus, hymenial layers, and cortex as shown in Fig. 2.

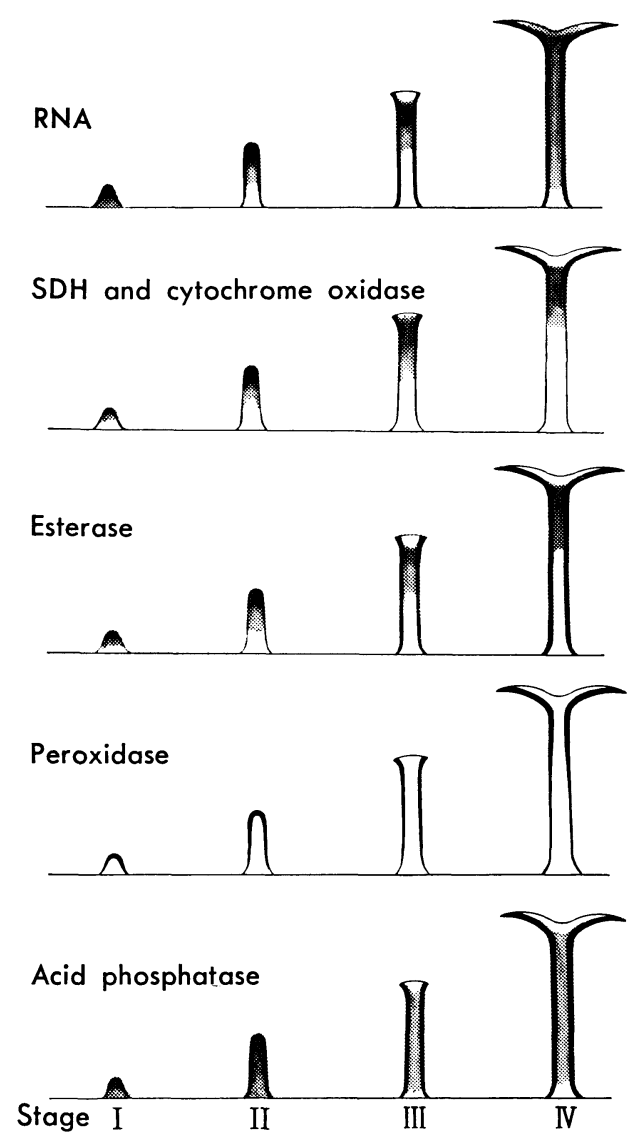

Fig. 2. Distribution of RNA, succinic dehydrogenase, cytochrome oxidase, esterase, peroxidase, and acid phosphatase in developing carpophore of Polyporellus brumalis. 


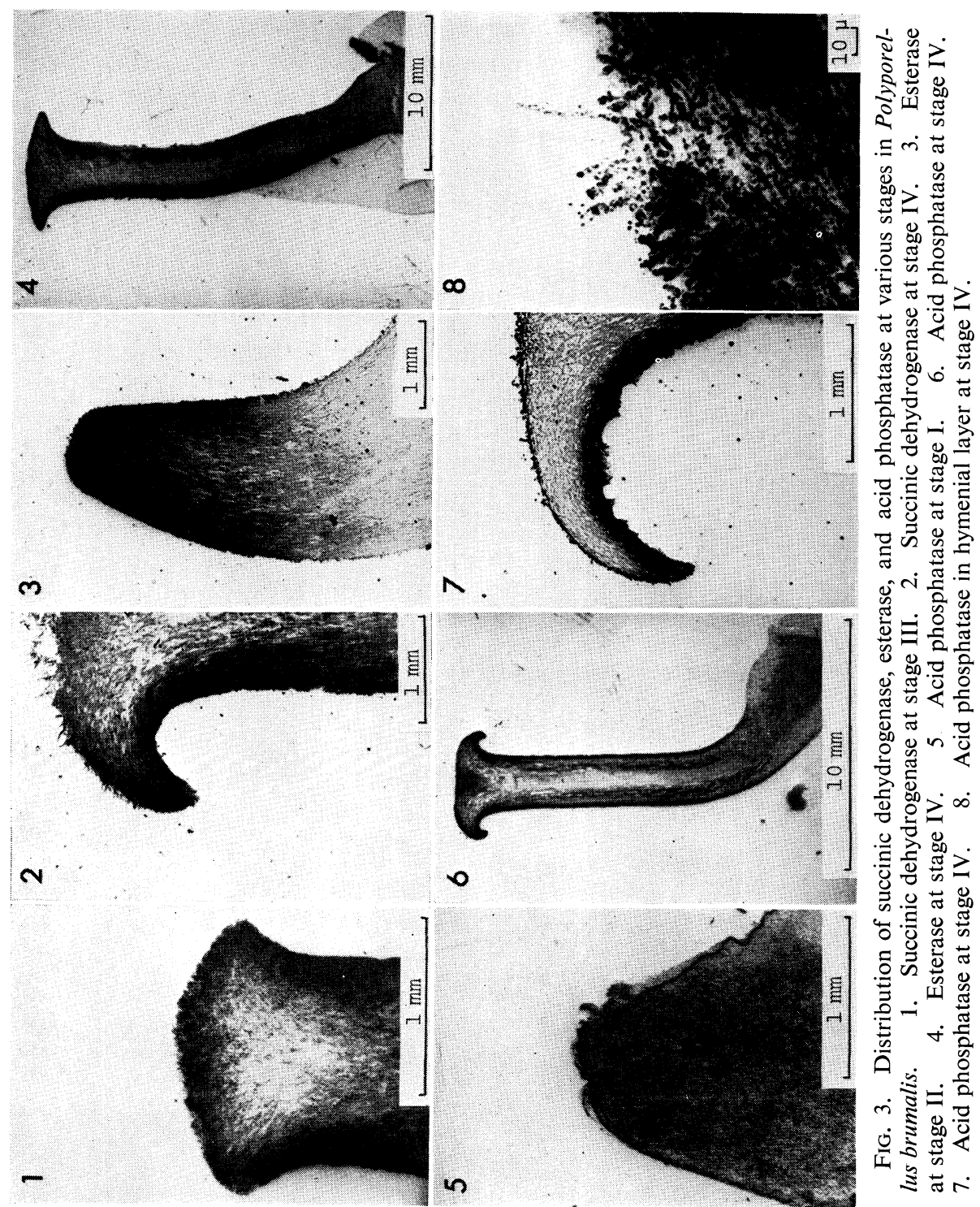


Distribution of succinic dehydrogenase, cytochrome oxidase, esterase, and peroxidase

These enzymes were intensively stained at the apical region of stipe at stage I to IV, and did so in hymenial layers at stages III and IV, as shown in Figs. 2 and 3. Esterase and peroxidase were stained also in the cortex.

Distribution of phosphatases

Alkaline phosphatase was not detected throughout the development. However, acid phosphatase was stained intensively at both of the hymenial pore-primordium and fully developed pores. Intense stain appeared also at the cortex (Figs. 2 and 3).

\section{DISCUSSION}

P. brumalis differs from C. kimurae in the mode of development of carpophore. In C. kimurae, stipe and pileus form simultaneously at an early stage of the carpophore development, and gills (hymenial layers) differentiate after pileus has formed. Basidiospores form at a later stage of development at which pileus grows rapidly. In $P$. brumalis, pileus differentiates from the tubular stipe which had been formed earlier. Hymenial layer formation follows the differentiation and development of the pileus. Basidiospores are produced soon after the hymenial layer has formed.

Kiтамото et al. $(3,4)$ reported that the growth zones of carpophore of Favolus arcularius (Fr.) Ames, which shows the carpophore development similar to that of $P$. brumalis, were found at the apex of stipe, margin of pileus, and hymenial layers, and that succinic dehydrogenase and cytochrome oxidase were detected in the growth zones of carpophore in this fungus. Therefore, the growth zones of carpophore of $P$. brumalis are considered to appear in the above-mentioned regions. In fact, RNA and some enzymes were detected at these zones. Similar results were obtained in $C$. kimurae (1). RNA, esterase, peroxidase, and acid phosphatase were detected also in the cortex of stipe in $P$. brumalis. These facts seem to suggest that the cortex is a physiologically active region.

Alkaline phosphatase was not detected in P. brumalis, but this enzyme was stained intensively in C. kimurae (1) and weakly in Flammulina velutipes (Fr.) Sing. (unpublished). This might be related to the difference in the mode of development of carpophore.

Acid phosphatase was detected in hymenial layers in $P$. brumalis soon after the layers formed (stage IV). In C. kimurae, acid and alkaline phosphatases were detected in gills (hymenial layers) at a stage when pileus grew remarkably. Phosphatase activities were detected in both fungal species at the stage of basidiospore formation. BULMER and LI (5) reported that phosphatase activity increased quantitatively during the meiotic process in Calvatia cyathiformis (Bosc.) Morg. These may show the role of phosphatase in basidiospore formation.

Developmental processes of the carpophore of Hymenomycetes are different in taxa, but the growth zones and locality of some enzymes in these zones seem to be similar as shown in P. brumalis and C. kimurae. Several studies on the carpo- 
phore formation and enzyme activities have been reported to date. Wessels (6) observed in Schizophyllum commune Fr. that activity of glucanase increased when primordia of carpophore formed. Leonard and PhILlips (7) reported that phenol oxidase activity in $S$. commune reached a maximum as the carpophore maturing. UNO and IsHIKAWA (8-10) described the role of adenylate cyclase, cyclic AMP phosphodiesterase, and protein kinase in the formation of fruit bodies in Coprinus macrorhizus Rea f. microsporus Hongo. These works have revealed the role of enzymes concerning carpophore formation in Basidiomycetes. In connection with these enzymic studies, further histochemical work would clarify the locality in which the enzymes play their roles and the significance of these enzymes in morphogenesis of Basidiomycetes.

\section{REFERENCES}

1) K. Komagata and M. Okunishi, J. Gen. Appl. Microbiol., 15, 231 (1969).

2) M. S. Burstone, Enzyme Histochemistry and Its Application in the Study of Neoplasms, Academic Press Inc., New York (1962), p. 293 and 429.

3) Y. Kitamoto, T. Horikoshi, and Z. KaSAI, Bot. Mag. (Tokyo), 87, 41 (1974).

4) T. Horikoshi, Y. Kitamoto, and Z. KasaI, Trans. Mycol. Soc. Japan, 14, 307 (1973) in Japanese.

5) G. S. Bulmer and Yu-Teh LI, Mycologia, 58, 555 (1966).

6) J. G. H. Wessels, Antonie van Leeuwenhoek J. Microbiol. Serol., 32, 341 (1966).

7) T. J. LeONARD and L. E. Phillips, J. Bacteriol., 114, 7 (1973).

8) I. UNo and T. IshiKaWA, J. Bacteriol., 113, 1249 (1973).

9) I. Uno and T. Ishikawa, Biochim. Biophys. Acta, 334, 354 (1974).

10) I. Uno, M. Yamaguchi, and T. Ishikawa, Proc. Natl. Acad. Sci. U. S., 71, 479 (1974). 